\title{
ÉTICA/ESTÉTICA EN FANTOMAS CONTRA LOS VAMPIROS MULTINACIONALES DE JULIO CORTÁZAR: UNA RELACIÓN SUPLEMENTARIA
}

Ethics/esthetic in Fantomas contra los vampiros multinacionales of Julio Cortázar: a supplementary relationships

Mary Fleur Mac-Millan Kuthe*

Resumen

El trabajo se centra en la lectura de Fantomas contra los vampiros multinacionales, obra de Julio Cortázar de gran complejidad, un híbrido que hasta el momento ha sido poco difundido. La obra presenta la problemática entre compromiso ético y compromiso estético, ya que se centra en la asistencia y participación de Julio Cortázar en las sesiones del Tribunal Russell y las violaciones a los derechos humanos en países latinoamericanos. La propuesta de lectura es la de considerar la relación de lo ético y lo estético desde el concepto derridiano de suplemento. Es decir, lo ético no sería un elemento marginal, tampoco habría una jerarquización entre ambos. El suplemento implica un nuevo modo de pensar toda relación binominal.

Palabras clave: conflicto ético/estético, Cortázar, suplemento.

Abstract

This work focuses on the interpretation of Fantomas contra los vampiros multinacionales, a narrative of great complexity by Julio Cortázar, a hybrid that is not so wellknown. The novel presents the problematic between ethical commitment and aesthetical commitment, since it is focused on the assistance and participation of Cortázar on the Russel Tribunal sessions and human rights violations in Latin American countries. The proposal for interpretation is to consider the relationship between the ethical and the aesthetical in light of the derridian concept of supplement. In other words, the ethical is not a marginal element, and there are no hierarchical differences between both. The supplement implies a new way of thinking about all binomial relationships.

Key words: ethical/aesthetical conflict, Cortázar, supplement.

\section{INTRODUCCIÓN}

Ética/estética conforman un binomio clásico del pensamiento occidental. Como tal, y siguiendo los postulados de Jacques Derrida, se trata de una estructura jerarquizante en que uno de los dos componentes ocupa el sitial dominante y el otro el marginal. O prima lo ético, y entonces lo estético es desplazado y marginalizado; o prima lo estético, y entonces lo ético es, a su vez, desplazado. Nos interesa hacer el ejercicio de pensar este vínculo entre lo ético y lo estético de un modo diferente. ¿Existe dicha posibilidad? Y más importante aún: ¿se da concretamente en algún texto determinado? Tal es el ejercicio que nos proponemos realizar en Fantomas 
contra los vampiros multinacionales, obra híbrida de Julio Cortázar que se remonta a 1975. Postulamos que ética y estética se relacionan en Fantomas a la manera del suplemento, modo que supera la jerarquía dicotómica. El concepto de suplemento, tomado del filósofo francés Jacques Derrida, nos ayudará a describir la estructura de Fantomas. Será necesario dilucidar previamente qué debemos entender por suplemento. Una vez hecho esto intentaremos mostrar la estructura del suplemento actuando concretamente en Fantomas. Primero en una macroinstancia y, luego, en una microinstancia. La macroinstancia está constituida por el texto ficcional y el Apéndice que Cortázar añade al final acerca de los resultados y acuerdos del Tribunal Russell $^{1}$. La microinstancia se da al interior del texto ficcional, en el que también se dejan ver relaciones de tipo suplementarias.

\section{UNA DESCRIPCIÓN GENERAL DE FANTOMAS}

Antes de entrar en el análisis mismo, es necesario un vistazo a la singularidad y a la textura de Fantomas. Primero, es posible señalar que el texto pertenece a las obras poco difundidas de Cortázar ${ }^{2}$, como Alto el Perú o Silvalandia. Su primera aparición data de junio de 1975 por la editorial Excélsior y durante muchos años la obra fue prácticamente imposible de hallar. Una posterior edición por Ediciones Destino (2002) ha permitido una relativa mayor difusión. Fantomas es un texto

\footnotetext{
${ }^{1}$ El Tribunal Russell fue un organismo creado por el filósofo del mismo nombre con posterioridad a la Guerra de Vietnam, también se le conoce como "Tribunal internacional sobre Crímenes de Guerra". Básicamente consiste en un comité formado por 25 destacados intelectuales de distintos ámbitos que se pronuncian acerca de conflictos bélicos basándose en sesiones testimoniales. En el texto se alude al Tribunal Russell 2, dedicado a los crímenes del Cono Sur, hubo tres sesiones: la primera en Roma en 1974, la segunda en Bruselas en 1975 y la tercera en Roma en 1976.

${ }^{2}$ A pesar de la poca difusión, Fantomas contra los vampiros multinacionales posee una buena acogida por parte de la crítica. En relación con las diferentes lecturas, Anne Connor (2013), en su artículo "Behaving Badly: Irreverent Play in Cortázar's Fantomas contra los vampiros multinacionales", señala: "Recientemente ha surgido un renovado interés por esta híbrida y creativa obra, la crítica ha explorado varios elementos literarios, artísticos, sociopolíticos e históricos del texto. María de Lourdes Dávila (2008), por ejemplo, ha analizado la complejidad de los múltiples niveles, y propone que este puede ser leído desde varias perspectivas: históricas, políticas o artísticas (p. 140). Igualmente, Marie-Alexandra Barataud (2009) argumenta que gracias a la combinación de intereses literarios, políticos y artísticos, la estructura del texto adviene en una escritura transgenérica única. Asimismo, Jaume Peris Blanes (Cortázar) aporta a la comprensión contextual de Vampiros multinacionales, realzando la relación con el debate intelectual en América Latina durante las décadas del sesenta y setenta, y finalmente, José Enrique Navarro (2012), mediante una lectura detallada de las diferentes versiones "evidencia la atención superficial que ha merecido la obra en sí, y más en particular las viñetas del cómic de Fantomas, que quedan relegadas de esta manera a la condición de material instrumental puesto al servicio del texto escrito". Además de los artículos citados por Connor, podemos mencionar: Fantomas contra Disney de Ana Merino (2013), y ya no tan recientes: "Libro de Manuel and Fantomas contra los vampiros multinacionales: Mass culture, Art, and Politics" (1981) y "Comic stripping: Cortázar in the Age of Mechanical Reproduction" (1998).
} 
híbrido, inclasificable, que mezcla un eje narrativo central ${ }^{3}$ con imágenes, recortes de diario, fotografías y dibujos. El eje central lo constituye el narrador protagonista llamado Julio Cortázar que acaba de asistir como integrante a las largas sesiones de testimonios del Tribunal Russel II en Bruselas. El narrador-personaje toma un tren de regreso a París y previo a esto compra en un quiosco cercano a la estación de trenes un cómic del súper héroe mexicano Fantomas, titulado: La inteligencia en llamas. Este cómic, inserto al interior del macrotexto, es de la autoría de Gonzalo Martré y Víctor Cruz. En este cómic ${ }^{4}$ se narra la historia de la extraña desaparición de los libros de las principales bibliotecas del mundo y tiene como protagonistas centrales a escritores como el propio Julio Cortázar, Octavio Paz y Susan Sontag, entre otros. Al final del texto y a modo de Apéndice, se añade el texto redactado como corolario a las sesiones del Tribunal Russell. Es un texto cien por ciento histórico-referencial y no ficcional.

\section{SUPLEMENTO}

A continuación esbozaremos brevemente el concepto central de nuestra lectura. La lógica del suplemento se entiende como una estructura que quiebra la lógica de la dominancia. Un primer significado de suplemento es "algo que completa o suma" (Culler, 1984, p. 94). En parte, la noción de suplemento es ambigua, ya que puede entenderse de dos maneras: "El suplemento es un extra no esencial, añadido a algo completo por sí mismo, pero el suplemento se añade para completar, para compensar de una falta con la que se supone se completa a sí mismo" (p. 94). El concepto de suplemento carga una cierta paradoja, y es que ese suplemento, en la medida en que se añade a algo ya existente, viene a poner en duda si ese algo estaba completo o no. El suplemento está bajo la lógica derridiana del "ni-ni", lo que se añade, es decir, el suplemento, pertenece y no pertenece al texto añadido. O dicho de otra forma, ni forma parte del texto, ni es un texto aparte. Ambos sentidos de suplemento operan simultáneamente, es decir, como añadido y como completación esencial $^{5}$. Ejemplo típico es el de la relación escritura/habla: "la escritura se puede añadir al habla solo si el habla no es una plenitud natural y autosuficiente, solo si hay ya en el habla una falta o ausencia que capacita a la escritura para actuar de

\footnotetext{
${ }^{3}$ Para un análisis acabado de los distintos niveles narrativos se recomienda el artículo de Marie-Alexandra Barataud (2009): "Del texto y de la imagen: la escritura transgenérica en Fantomas contra los vampiros multinacionales de Julio Cortázar".

${ }^{4}$ En otro artículo, titulado "La función del Cómic en Fantomas contra los vampiros multinacionales: del fetiche al duelo" (por aparecer en Revista Iberoamericana de Literatura) nos abocamos, precisamente, al rol del cómic al interior de esta obra.

${ }^{5}$ Jacques Derrida desarrolla esta doble significación extensamente en De la Gramatología. Su estudio se centra en una compleja lectura de Rousseau, para los fines más concretos que nos guían, lo esencial se puede seguir en las páginas 184 a la 195 (Derrida, 1971). La doble significación del suplemento se reduce a la noción de "excedente", por un lado, y, por otro, a la idea de "suplir": "El suplemento se añade [...]. Pero el suplemento suple" (p. 185).
} 
suplemento" (p. 94). Entendido así, el suplemento no es un mero añadido que complementa, "revela una carencia o ausencia inherente [...] el extra adicional se convierte en una condición esencial de lo que suplementa" (p. 95).

\section{ANÁLISIS}

Veamos ahora cómo opera este suplemento al interior de Fantomas contra los vampiros multinacionales. El texto "principal" -y decimos "principal" entre comillas, ya que precisamente de lo que aquí se trata es de cuestionar este sitial de dominioconsta de 77 páginas $^{6}$ que van puestas al comienzo del libro. Luego, en un segundo lugar, es decir, al final del texto, está ubicado el Apéndice, que tan solo lleva este título. Consta de 16 páginas. Es decir, si nos basamos en criterios de orden (primero, segundo/ al comienzo al final) y de cantidad (más, menos), el Apéndice, al ir al final y al ser más breve, ocupa el lugar secundario en el binomio texto/apéndice. Desde un criterio semántico, su desplazamiento a segundo nivel es más obvio, porque "Apéndice" apunta a un añadido a algo principal. En este binomio y en una primera mirada muy general, el texto es literario y el apéndice es claramente político o ético. De tal manera que estructuralmente lo literario prima por sobre lo ético. ¿Qué contiene concretamente este Apéndice? ¿De qué manera se anexa al texto? El Apéndice es un resumen de lo tratado y las conclusiones a las que se llega en las reuniones en el Tribunal Russell. Se menciona la composición del tribunal y sus miembros. El lenguaje es extremadamente legal y parco, y se divide en A: "Violación de los derechos del hombre y de los derechos de los pueblos" (p. 88) con subdivisiones 1, 2, 3, 4 y 5. Le sigue B: "Las causas económicas de la violación de los derechos del hombre y del derecho de los pueblos" (p. 91). Luego se describen las conclusiones: "Por todos estos motivos, el tribunal sobre los derechos del hombre [...]" (p. 95) y se enumeran las determinaciones centrales, luego viene "Sobre los derechos de los pueblos" (p. 96) y se termina con las exigencias de liberación y de medidas concretas. Resumiendo: Apéndice es un texto de ciertos rasgos leguleyos, de un lenguaje sobrio, enumerativo, en que se puntea una situación histórica concreta, se llega a conclusiones y determinaciones. Nos detenemos en esta descripción ya que es importante el contraste que se genera con el lenguaje del texto literario. Son textos estilísticamente completamente diferentes, además del hecho obvio que el Apéndice no es de la autoría de Cortázar. Ahora bien, ¿en qué momento se genera un primer vínculo entre ambos? Desde el comienzo del texto "literario", ya en la primera página del relato, nos enteramos de la existencia del Apéndice gracias a una nota a pie de página. Arriba dice: "La reunión de Bruselas del Tribunal Russell II [aquí aparece la nota 1] había terminado a mediodía, y el narrador de nuestra fascinante historia tenía que regresar a su casa de París [...]” (p. 5). La cita a la que se nos remite a pie de

\footnotetext{
${ }^{6}$ Citamos de la edición de editorial Destino (2002).
} 
página es la siguiente: "El lector interesado en conocer detalles sobre este tribunal los encontrará en el Apéndice (p. 81-97). Un consejo amistoso: lea el apéndice al final, para qué apurarse si aquí va todo de lo más bonito" (p. 5). Lo que acabamos de hacer, es un primer gesto de inversión en una relación de binomio tradicionalmente jerárquica. Hemos subido la nota a pie de página al texto superior, dándole así una importancia o relevancia que no tenía. La nota a pie de página cobra vital importancia. El hecho de enterarnos de la existencia del Apéndice mediante la nota marca una relación de dominio entre el texto y este, ya que de hecho hay muchos lectores que no leen las notas a pie de página. Ahora, la opción a su lectura antes o después de la lectura del texto "principal" abre una posibilidad de efecto de lectura distinta. Sin embargo, de momento, nos centraremos en el efecto de su lectura una vez finalizada la del texto principal.

Hemos sugerido que el Apéndice se relaciona con el "texto principal" a manera de suplemento, vayamos ahora a dilucidar esta afirmación. Si hay suplemento, recordemos, significa que el texto principal no se entiende por sí solo, ya que necesita de este apéndice para ser comprendido en su cabalidad. Para la reflexión que nos ocupa, esto significa que la relación entre estética (texto principal) y ética (apéndice), es suplementaria y no jerárquica. Es decir, se revela una relación en la que el texto estético está necesitado de lo ético, en donde lo literario no se comprende desde sí mismo, sino "en" y "desde" esa relación establecida con lo ético. Esta propuesta de lectura se contrapone con algunas recepciones críticas en las que solo se valora la presencia del Apéndice, y se desecha el texto literario-principal como mera excusa para introducir el texto más político. Visto así, el Apéndice sería el texto central o primario, lo que vale la pena; y la historieta, el texto literario, sería solo un enganche, algo superfluo. En esta sentencia lo literario se supedita a lo ético/político, ocupando lo ético un rol central y lo literario el lugar marginal o desplazado ${ }^{7}$. Esta inversión corresponde a un primer movimiento esperado y necesario dentro de los procedimientos típicos de la deconstrucción, citamos a Derrida de su texto Posiciones: "Deconstruir la oposición, significa, en un momento dado, invertir la jerarquía" (Derrida, 1977, p.55). Sin embargo, y siguiendo al mismo Derrida, la relación suplementaria implica ir un paso más allá, la deconstrucción debe (como cita Culler): "poner en práctica [...] un corrimiento general del sistema. Será solo con esa condición como la deconstrucción podrá ofrecer los medios para intervenir en el

\footnotetext{
${ }^{7}$ Jaume Peris (2012), en su artículo "Cortázar: entre la cultura pulp y la denuncia política", también menciona, de alguna manera, esta supuesta "instrumentalización" de la narración como vía para transmitir el mensaje más "político": "Es probable, de hecho, que la tonalidad ligera del texto, su apuesta directa por el divertimento y el placer narrativo, así como su utilización irónica del cómic y la estética pulp, tuvieran como objetivo captar la atención del lector medio sobre lo que realmente le interesaba en ese momento: la declaración del Tribunal Russell, la situación de represión generalizada que se estaba viviendo en Chile y la escalada de la violencia política que estaba ganando Argentina. Esa naturaleza hasta cierto punto secundaria de la narración -con un objetivo pragmático muy claro, más allá del propiamente literario- hace de Fantomas... un texto extraño en la producción cortazariana (...)” (p. 100).
} 
campo de las oposiciones que critica" (Culler, 1984, p. 392). ¿Ocurre este corrimiento del sistema en Fantomas? Por "corrimiento" entendemos, en este caso, el que se rompa la relación jerárquica entre lo literario y lo ético, y que lo literario adquiera nuevas significaciones y aristas a la luz de lo ético. Concretamente, ¿cómo ocurre esto entre lo que hemos denominado "texto principal/literario" y "texto secundario ético o Apéndice"? El corrimiento ocurre por medio de la inesperada imbricación de los niveles de realidad en el texto principal. La clave para entender la suplementariedad del Apéndice en el texto opera mediante los cambios en los planos de realidad. Veamos: en un comienzo distinguimos tres niveles de realidad, los que van de un extremo de mayor a menor grado de ficcionalidad (ver Tabla 1).

Tabla 1. Niveles de realidad

\begin{tabular}{|c|c|l|}
\hline Nivel 1 & Ficción & $\begin{array}{l}\text { Cómic: “La inteligencia en llamas" } \\
\text { Autores: Martré y Cruz }\end{array}$ \\
\hline Nivel 2 & $\begin{array}{c}\text { Semificción } \\
\text { (elementos autobiográficos) }\end{array}$ & $\begin{array}{l}\text { Relato del personaje JC regresando de } \\
\text { Bruselas a París } \\
\text { Autor: Julio Cortázar }\end{array}$ \\
\hline Nivel3 & No ficción & $\begin{array}{l}\text { Apéndice: Informe del tribunal Russell } \\
\text { Autor: Tribunal }\end{array}$ \\
\hline
\end{tabular}

El cómic de Fantomas, inserto al interior del texto general llamado "La inteligencia en llamas", constituye la Ficción 1, es el texto más alejado de la realidad, sus personajes son héroes de tiras cómicas y el tema una fantasía en torno a la desaparición de libros en las principales bibliotecas mundiales. La Ficción 2, un poco más cercana a la realidad, en la medida en que posee rasgos autobiográficos, la constituye la historia del narrador-personaje, Julio Cortázar, quien vuelve agotado a París después de su asistencia al tribunal Russell. El tercer nivel de realidad es el de no ficción, constituido por el Apéndice y equivale a una salida del corpus ficcional compuesto por ficción 1 y 2 . Ahora bien, en un comienzo se dan saltos entre el nivel 1 y el 2, es decir, los personajes del nivel 2 aparecen caricaturizados en el cómic de Fantomas. Luego, los personajes de la Ficción 2, Cortázar y Susan Sontag, entre otros, establecen diálogos con Fantomas, personaje de la Ficción 1. Así, ya hacia mediados del texto se borran las diferencias entre F1 y F2 y se da una especie de supraficción y permeabilización de ambos niveles. Hasta aquí nada tan especial, el giro más significativo aparece en la página 43, cuando se da el salto de la F2, ya contaminada por la F1, hacia el nivel 3 de No ficción, es decir, el Apéndice. En un diálogo telefónico, Susan Sontag (personaje de F1), insiste en plantearle el tema del Tribunal al personajeCortázar (F2), señalando la necesidad de que Fantomas se entere de estos temas. Aquí aparece la primera mención al Tribunal Russell al interior de la ficción:

Mi querida, vuelvo de Bruselas tan cansado, tal vez sepas que... - Lo sé, esta pieza está llena de diarios y yo sé leer si las letras son lo bastante grandes. El Tribunal Russell en Bruselas, verdad. La segunda reunión sobre los problemas 
latinoamericanos. Una sentencia muy dura y muy clara contra Ford, contra Kissinger, contra las sociedades vampiras, la ITT y el resto (Cortázar, 2006, p. 43).

A lo que Cortázar repara: "Nos estamos saliendo del tema", ya que el tema sería Fantomas y la desaparición de libros, pero Sontag insiste: "¿saliendo del tema? Si alguna vez estuvimos en el tema es ahora" (p. 43). Más adelante, en la página 47, se da un nuevo salto significativo, esta vez de F2 a F1. El escritor Moravia, habiéndose leído a él mismo en el cómic de Fantomas, dice que en vez de haber dicho "Fantomas, haz algo por el amor al arte", debió haber dicho "por amor al hombre": "donde dice arte yo hubiera debido decir hombre". Es significativa esta corrección de la ficción más extrema a la luz de una ficción semiautobiográfica, que anhela cambiar el curso de lo ficcional desde la realidad. Las piezas del puzle calzan ya de lleno en la página 48, en donde por fin se da la conexión y fusión entre los tres niveles de realidad: F1, F2 y NF3. Nuevamente en diálogo con Sontag, esta le hace ver que el responsable de la quema de libros no es un tal Steiner, personaje del cómic, sino que:

Julio, Julio, ¿quién es verdaderamente Steiner? ¿Cómo se llaman los que el Tribunal Russell acaba de condenar en Bruselas? -Se llaman de mil, de diez mil, de cien mil maneras- dijo el narrador con la misma voz cansada [...] pero se llaman sobre todo ITT, sobre todo Nixon y Ford, sobre todo Henry Kissinger o CIA o DIA, se llaman sobre todo Pinochet o Banzer o López Rega, sobre todo General (p. 48).

Al conectar la F1 (el cómic de Fantomas) con la NF3 (el Apéndice), mediada por la F2 (el personaje Cortázar) se produce una fusión compleja, y es que se muestra como la ficción (creación estética) "necesita" de la No Ficción para alcanzar toda su potencialidad significativa. La historieta de Fantomas cobra una nueva lectura a la luz de la NF. Fantomas, el súper héroe mexicano, ve inicialmente la problemática de un modo muy simple, y el narrador de la F2 también, solo la conexión explícita entre los tres niveles logra un salto hacia una cuarta realidad que es más que la suma de los tres niveles (ver Tabla 2). Ahora es Fantomas, personaje de la F1, quien acude al narrador de la F2, para que le informe de su trabajo en el Tribunal Russell (NF): "Por eso quiero enterarme bien de lo que hicieron ustedes los hipercerebrales en el Tribunal Russell (p. 53)", a lo que Cortázar contesta: "-Mirá en los apéndices y encontrarás lo necesario- dijo el narrador mostrando las páginas finales de este mismísimo volumen" (p. 53). Aquí ocurre un desplazamiento del espacio marginal ocupado por el Apéndice en la página cinco inicial, en donde se hacía referencia a su existencia mediante nota a pie de página. Ahora el Apéndice se "sube" al texto, ocupando un lugar central. El Apéndice irradia significación y es el texto a la luz del que las acciones del héroe Fantomas adquieren orientación y base. El Apéndice ha dejado de serlo y penetra en la ficción, dislocándola y cambiando su rumbo novelesco y su trama interna. Fantomas redireccionará sus pesquisas hacia las sociedades multinacionales, ya que Cortázar- personaje le insistirá: "Si querés una síntesis, te la hago en tres palabras: las sociedades multinacionales. La ITT puede servirte de 
resumen" (p. 53). Es decir, la presencia del Apéndice en los dos niveles ficcionales no es solo un tema, sino que contamina el accionar de los personajes: Cortázar informa a Fantomas de las principales resoluciones del Tribunal Russell y, llegado a este punto, el curso de las acciones de Fantomas se centran en el fastidiar y amenazar a diversos organismos internacionales. El cómic salta así de la pueril quema de libros inicial a la persecución de la CIA y la junta militar. El accionar solitario y heroico de Fantomas pasa a un segundo plano cuando se insiste en la toma de conciencia de todos los sujetos. Y ahora vendrá el último salto en los planos, ahora es el mismo texto del Apéndice, de modo textual, el que entrará en la ficción, haciéndose oír como una voz que contamina e interfiere una comunicación telefónica: "El Tribunal Russell condena a las personas y autoridades que se han amparado del poder por la fuerza y que lo ejercen despreciando los derechos de sus pueblos. Condena por estos cargos a las personas que ejercen actualmente el poder en Brasil, Chile, Bolivia, Guatemala, Haití, Paraguay y la República Dominicana" (p. 74). A partir de esta intervención, de esa voz que se cuela en la conversación telefónica, se suman más voces, con acento argentino, peruano, de distintas nacionalidades, y nuevamente una voz con el texto del Tribunal. Así se genera una especie de coro, de supravoz, que va más allá de un individuo particular. El "texto" del Apéndice aparece -ya no citado como texto-, sino como voz-personaje, como un sujeto más en un diálogo. Resumamos, en un comienzo el Apéndice ocupa un lugar extratextual y marginal, en una segunda instancia se inserta al interior de los niveles ficcionales haciendo que cambie el rumbo narrativo y el accionar de los personajes de ficción y, en una última instancia, aparece ya directamente como una presencia concreta desde una voz-personaje que inunda el texto principal. No es, como podría pensarse, una mera inversión entre texto principal y Apéndice, no ocupa ahora el Apéndice el lugar del texto y este el del Apéndice. Es una relación suplementaria, que revela cómo lo estético ficcional se ve enriquecido y fortalecido por la intromisión de lo ético político. Sin el Apéndice, Fantomas sería un libro soso e insípido, a lo más un elegante y virtuoso juego literario. Pero, a su vez, el Apéndice, sin el texto ficcional, sería un texto seco, árido y con escasa capacidad de impacto. El "extra adicional", el elemento marginal, "se convierte en condición esencial de lo que suplementa" (Culler, 1984, p. 95). El plus o ese corrimiento del que hablábamos, es la integración, el paso de un texto leguleyo que hay que leer al final, si se quiere, a la transformación de voz y de sujeto que forma parte del tejido narrativo "central". En esta integración de ambos elementos no hay una instrumentalización de lo narrativo para difundir el Apéndice, como comentan algunos críticos. Hay una unidad superior en que tanto lo narrativo como el Apéndice se enriquecen y salen ganando. 
Ética/Estética en Fantomas contra los vampiros multinacionales de Julio Cortázar

Tabla 2. Saltos en los niveles

1. Del nivel 2 al 1

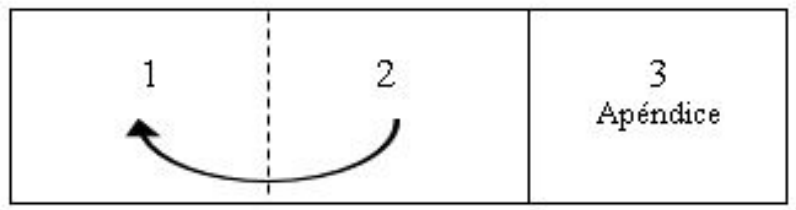

2. Se borranfronteras entre 1 y 2

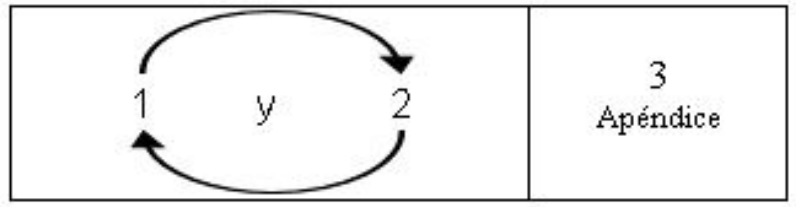

3. Se hacen referencias al nive1 3

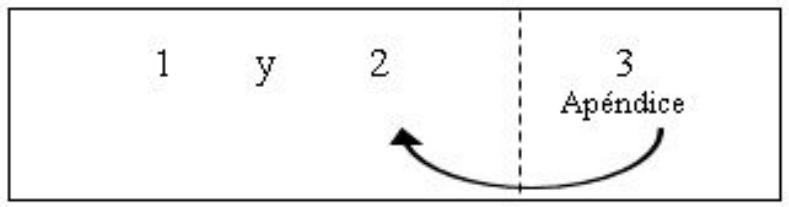

4. Fusión de 3 niveles

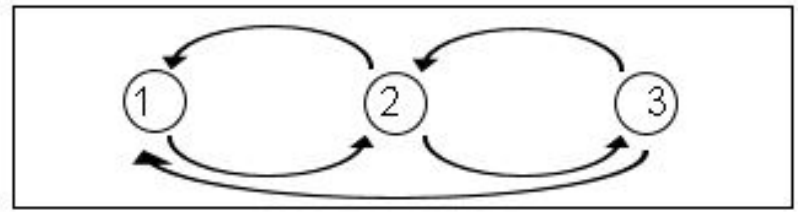

Habíamos mencionado que la relación suplementaria ocurre en dos niveles: un primer nivel que llamábamos macroinstancia -y es el que acabamos de revisar, entre texto principal y Apéndice- y en un segundo nivel o microinstancia. Este segundo nivel ocurre al interior del texto literario, en él observamos al menos tres relaciones suplementarias (ver Tabla 3). Primera: entre el personaje "Julio Cortázar" y el súper héroe Fantomas. Segunda: entre el texto netamente narrativo y el cómic inserto "La inteligencia en llamas". Tercera: entre el texto narrativo y las imágenes insertas (ya sea dibujos o fotografias). 
Tabla 3. Relaciones suplementarias

1. Macroinstancia: entre texto principal y apéndice

\begin{tabular}{|c|c|}
\hline $\begin{array}{c}\text { Texto } \\
\text { principal }\end{array}$ & Apéndice \\
\hline
\end{tabular}

2. Microinstancias: al interior del texto principal

\begin{tabular}{|ll|}
\hline 2.1. & Entre Julio Cortázar y Fantomas \\
\hline 2.2. & Entre texto narrativo y cómic \\
\hline 2.3. & Entre texto e imágenes \\
\hline
\end{tabular}

En relación con la primera podemos constatar en un comienzo que ambos personajes se mueven en mundos opuestos: Julio Cortázar es un intelectual-escritor cansado y que solo desea sumirse nuevamente de lleno en su vida de placeres de pequeño burgués. Fantomas es un hombre de acción, quiere por sobre todas las cosas cambiar la realidad, operar directamente en ella. No pueden ser más opuestos, sin embargo, a medida que la trama avanza, esta oposición se torna suplemento. Fantomas, el héroe de acción necesita las directrices del intelectual de salón para darle orientación a su quehacer. La acción desbocada de Fantomas no conduce a nada si no es acompañada por la fría mente del intelectual. Al final, ambos personajes se unen en la metáfora de la mirada en común. Fantomas se despide de Julio Cortázar y en ese momento ambos ven a un niño jugando: "Por el agujero de la ventana miró hacia la calle desierta; sentado en el cordón de la vereda un niño rubio jugaba con unas piedritas [...]. El narrador vio que Fantomas, de pie en el tejado de la casa de enfrente, miraba también al niño" (p. 80-81). La imagen del niño está ahí para representar el futuro que ambos personajes, Fantomas el héroe y Cortázar el escritor, pretenden cambiar y mejorar. La mirada de ambos se cruza en el niño-futuro, mostrando cómo ambas posturas frente a la realidad no son tan opuestas como parecen en un comienzo, y que, por el contrario, una necesita de la otra. Misma relación suplementaria se da entre los otros binomios nombrados: texto/cómic y texto/imágenes. El cómic, en un primer momento se consideró de modo marginal, como un subgénero de mera distracción o entretenimiento un tanto infantil y tontón: "parecía casi idiota abrir una revistita llena de colorinches" (p. 12). A medida que el personaje avanza en su lectura, el cómic cobra fuerza y entra literalmente en la narración para demostrar lo que en ella hacía falta: un compromiso más directo con la difusión de los resultados del Tribunal Russel. El cómic funge así como suplemento, revelando la falta del otro elemento del binomio. En el caso de las imágenes, estas revelan elementos faltantes del lenguaje como forma de comunicar una experiencia compleja, y acuden en ayuda de las palabras. Buen ejemplo de esto es cuando Cortázar intenta explicarle a Fantomas, hombre de acción, el rol nocivo de las sociedades internacionales, y llegado a ese punto se inserta una imagen a modo de "metáfora visual". Y Cortázar dice: "Así las veo yo" y en la página siguiente se observa una imagen en blanco y negro en la que una mano empuñando un cuchillo lo hunde en la pupila de un ojo. La imagen, en extremo violenta, logra expresar la funesta y castradora 
historia de América. Así, la relación suplementaria no solo se da entre el texto y el Apéndice, sino que también al interior del texto en las tres variedades esbozadas.

Hecha esta lectura a Fantomas, insertemos ahora brevemente el problema dentro de un marco mayor: tal es la búsqueda del propio Cortázar por una vinculación más armónica entre lo ético y lo estético en su quehacer como escritor. Si bien es cierto que suele encasillarse la obra de Cortázar dentro de la literatura fantástica, no son pocos sus intentos por conciliar sus preocupaciones literarias con una contingencia histórica concreta. Las obras más representativas dentro de estos intentos son: Libro de Manuel, Nicaragua tan Violentamente dulce y Alto el Perú en formato de libro. También hay varios cuentos que se hacen cargo de este giro en su búsqueda literaria. El más emblemático y que le costó la prohibición de ingresar a su país es "Segunda vez". También hay que destacar "Reunión", "Apocalipsis de Solentiname", "Recortes de prensa" y "Grafitti",. También son numerosos los artículos, las cartas y ponencias en que Cortázar se refiere al tema. Algunos ejemplos más conocidos: Viaje alrededor de una mesa, Policrítica en la hora de los chacales, "Literatura en la revolución y revolución en la literatura: algunos malentendidos a liquidar", la tan citada "Carta a Roberto Fernández Retamar" (acerca de la "situación" del intelectual latinoamericano), la "Carta a Haydée Santamaría", etcétera. En todos estos textos y en innumerables otros, lo central es que Cortázar defenderá siempre la libertad del escritor en su proceso creativo por sobre servilismos burócratas. Jaume Peris, en un estudio dedicado a Libro de Manuel lo sintetiza así: "Cortázar había siempre hecho hincapié en el paralelismo entre la exploración política y la exploración literaria, vinculando su trabajo de experimentación formal con la búsqueda de una nueva subjetividad" (Peris, 2005-2006, p. 145).

Hay varios autores que se dedican a mostrar un recorrido vital cortazariano bajo este conflicto ${ }^{9}$, el que se puede resumir muy sucintamente de la siguiente manera: una primera etapa en donde prima lo estético y cierto hedonismo sin ningún atisbo de compromiso ético o político; un segundo momento -que Omar Prego denomina como el "camino a damasco"- en el que hay una especie de conversión hacia las preocupaciones más históricas, políticas y éticas. Este giro se suele vincular con la revolución cubana, como hito histórico, aunque el asunto es más complejo, ya que el vuelco es sutil y tiene antecedentes previos. Citamos:

La revolución cubana, por analogía, me mostró entonces y de una manera muy cruel y que me dolió mucho, el gran vacío político que había en mí, mi

\footnotetext{
${ }^{8}$ Los cuentos mencionados son los que claramente admiten una lectura de contingencia. Sin embargo, y como señala el crítico Standish: "una lectura de obras tempranas, realizada a la luz de lo que sabemos de la evolución política de nuestro autor, hace que las interpretaciones políticas resulten sumamente tentadoras. De hecho, sobran estudios que se basan en el supuesto de que por debajo de los primeros cuentos de Cortázar late una intención política, aunque sea inconsciente. La banda, Las Ménades y Las puertas del cielo son ejemplos de otros cuentos que han sido interpretados como textos políticos".

${ }^{9}$ Destacamos los artículos de Peter Standish $(1997,2004)$.
} 
inutilidad política. Desde ese día traté de documentarme, traté de leer, de entender: el proceso se fue haciendo paulatinamente y a veces de una manera inconsciente. Los temas donde había implicación política o ideológica, más que político se fueron metiendo en mi literatura. Ese es un proceso que se puede apreciar a lo largo de los años (Cortázar y Prego,1997, p. 209).

Decíamos que el problema es más sutil, ya que no se trata tan solo de un vuelco hacia lo histórico entendido exclusivamente como un hecho político y social ${ }^{10}$. Cortázar promulgó siempre, y de ahí sus incontables roces con la izquierda más dura e intransigente, la necesidad de un cambio de orden más radical. Junto con un llamado a la libertad en el oficio, a la búsqueda de Cortázar por armonizar las esferas mencionadas subyace un anhelo vital que implica una reconsideración total de lo que se entenderá por realidad. Recordemos el ya tan citado fragmento de la carta a Roberto Fernández Retamar: "De la Argentina se alejó un escritor para quien la realidad, como lo imaginaba Mallarmé, debía culminar en un libro; en París nació un hombre para quien los libros deberán culminar en la realidad" (1994, p. 36).

Ahora bien, Cortázar siempre fue consciente de la complejidad del binomio ética /estética:

En la mayoría de los libros llamados comprometidos o bien la política (la política, la parte del mensaje político) o anula o empobrece la parte literaria y se convierte en una especie de ensayo disfrazado o bien la literatura es más fuerte y apaga, deja en una situación de inferioridad al mensaje, a la comunicación que el autor desea pasar a su lector (1997, p. 214-215).

Este conflicto le parece a Cortázar "uno de los problemas más apasionantes de la literatura contemporánea" (1997, p. 215). El "problema" fue abordado, como ya mencionamos, en varias ocasiones y con resultados disímiles. Fantomas ocupa un lugar valioso dentro de esta búsqueda y puede vincularse a uno de sus más discutidos intentos. Nos referimos a la novela Libro deManuel, sobre la que Jaume Peris afirma:

La novela de Julio Cortázar Libro de Manuel (1973) fue sin duda el esfuerzo más importante de su autor por conectar su concepción de la ficción literaria con el contexto de agitación y violencia política de los últimos años sesenta y principios de los setenta en América Latina ( p.143).

Aunque la crítica suela evaluar tibiamente el logro final de Libro de Manuel, más que la evaluación, lo que interesa son los procedimientos, semejantes, en cierto punto,

\footnotetext{
${ }^{10}$ Claro ejemplo de un compromiso que va más allá de un quehacer concreto político lo podemos ver en el cuento El perseguidor. En una entrevista con Omar Prego (Cortázar y Prego, 1996), Cortázar sitúa el origen de su giro desde lo fantástico hacia una conciencia distinta en el cuento mencionado. A lo que Prego responde con sorpresa: "Yo, así, a primera vista, no veo una relación muy clara..." (p. 210). Y Cortázar contesta: "Bueno, en El perseguidor la política no tiene absolutamente nada que ver, la ideología tampoco. Pero sí tiene que ver, por primera vez en lo que yo llevaba escrito hasta ese momento, una tentativa de acercamiento al máximo a los hombres como seres humanos" (p. 210).
} 
con los utilizados en Fantomas. En la novela en cuestión Cortázar une dos niveles de realidad (ficción e historia) mediante el recurso de la inserción de recortes de prensa. Es este mismo recurso (fusión de niveles de realidad) el que, como fue descrito en detalle en el análisis, se verá maximizado posteriormente en Fantomas. Así, leemos Fantomas (de1975) a la luz de lo intentado en Libro de Manuel (en 1973). Si la unidad entre el universo novelesco y la historia concreta no lograría convencer del todo en la novela ${ }^{11}$, en Fantomas, y esta es nuestra propuesta final de lectura, se acerca cada vez más hacia la meta tan ansiada. En Fantomas, Cortázar, mediante el suplemento, va más allá de la mera intrusión de los niveles de realidad. La unión de diversos niveles ya no queda en una mera técnica criticable por su posible arbitrariedad. El suplemento muestra la indisolubilidad de lo disímil: su intrínseca necesidad y convergencia. El suplemento es el camino más logrado para la tan ansiada unidad.

La opción por dejar esta breve contextualización cortazariana al conflicto ético /estético, para el final, es metodológica, así podemos situar o valorar la relación suplementaria en Fantomas con mayor perspectiva. La relación suplementaria, creemos, si bien no termina de "solucionar" del todo el conflicto, permite que el escritor, y aquí volvemos a citar a Cortázar:

No renuncie a nada, no traicione nada, sino que sitúe su visión en un plano desde donde sus valores originales se insertan en una trama infinitamente más amplia y más rica y por eso mismo [...] ganan a su vez en amplitud y riqueza, se recobran en lo que pueden tener de más hondo y de más valedero (1994/Tomo III, p. 40).

Así, Fantomas se inserta al interior de la búsqueda total de Cortázar por ampliar los límites de la realidad. El binomio ética/estética adquiere una mayor luz al entenderse como un eje central dentro de esta tentativa.

Universidad Adolfo Ibáñez*
Sede Viña del Mar
Pedro de Valdivia 305, Limache (Chile)
mary.macmillan@uai.cl

\section{OBRAS CITADAS}

Barataud, Marie-Alexandra. (2009). "Del texto y de la imagen: la escritura transgenérica en Fantomas contra los vampiros multinacionales de Julio Cortázar". Journéesd'etudes et colloques du SAL III. En línea; disponible en http://www.crimic.paris-sorbonne.fr/sal/spip.php?article215

\footnotetext{
${ }^{11}$ Esto es de hecho discutible y demandaría una revisión minuciosa de la crítica que no deseamos realizar aquí. Pero tan solo una muestra proveniente de Peter Standish: "El compromiso personal de Cortázar, sin embargo, fue doble, compromiso con dos visiones éticas difícilmente reconciliables, y la tensión entre ellas, como acabamos de ver, persiste hasta el final de su vida. Algunos de los escritos en los que el autor intenta resolver esta tensión [...] son verdaderos éxitos; otros, como el Libro de Manuel, lo son a medias" (11)
} 
Cortázar, Julio. (2002). Fantomas contra los vampiros multinacionales. Buenos Aires, Argentina: Destino.

— (1994). Obra Crítica/3.Madrid, España: Alfaguara.

Cortázar, Julio y Prego, Omar. (1997). La fascinación de las palabras. Buenos Aires, Argentina: Alfaguara.

Connor, Anne. (2013). "Behaving Badly: Irreverent Play in Cortázar's Fantomas contra los vampiros multinacionales". Ciber Letras. Revista de Crítica Literaria y de Cultura 31.

Culler, Jonathan. (1984). Sobre la deconstrucción. Madrid, España: Cátedra.

Dávila, María Lourdes. (2008). "Alguien se pierde en el laberinto cosmicómico de Fantomas, ¿pero quién?”. Revista Iberoamericana VIII, 29,123-142.

Derrida, Jacques. (1977). Posiciones. Valencia, España: Pre-Textos. (1971). De la Gramatología. Buenos Aires: Siglo XXI.

José Enrique, Navarro. (2012). “Adversidades transatlánticas: vida editorial de Fantomas contra los vampiros multinacionales de Julio Cortázar". Ciberletras 29.

Peris, Jaime. (2012). "Cortázar: entre la cultura pulp y la denuncia política". Estudios Filológicos. 50, 95-112.

_ (2005-2006). "Libro de Manuel, de Julio Cortázar, entre la revolución política y la vanguardia estética". Cuadernos de Investigación Filológica. 31-32, 143-161.

Standish, Peter. (2004). "La (Est)ética de Julio Cortázar". Études romanes de Lund. 70. - (1997). "Los compromisos de Julio Cortázar". Hispania. Vol. 80. 3, 465-471. 